\title{
A Convenção de Viena sobre a Sucessão de Estados em Matéria de Bens, Arquivos e Dívidas do Estado
}

\section{(8 de abril de 1983)}

Gustavo Zanini

Professor Assistente Doutor de Direito Internacional na Faculdade de Direito da Universidade de São Paulo

\begin{abstract}
RESUMO: I - Premissas sobre a atualidade do tema da Sucessão de Estados no âmbito do Direito Internacional. - II - Caracteres gerais e propósitos da Convenção. - III Campo de aplicação da Convenção: A) Determinação do alcance da Convenção. - B) A transferência dos bens de Estado. - C) A transferência dos arquivos de Estado. - D) A transferência das dívidas de Estado. - E) A regulamentação das controvérsias. - IV) - Conclusões
\end{abstract}

RÉSUMÉ: I - Prémisses sur l'actualité du thème de la succession d'État dans la sphère du droit internacional. - II - Caractères généraux et objectifs de la convention. - III Domaine d'application de la convention; a) détermination de la portée de la convention: b) le transfert des biens de l'État; c) le transfert des archives de l'État; d) le règlement des controverses. - IV - Conclusions.

\section{I - Premissas sobre a atualidade do tema da Sucessāo de Estados no âmbito do Direito Internacional}

O persistente interesse que os Estados da Comunidade Internacional têm demonstrado no contexto da codificação do direito internacional e seu desenvolvimento progressivo revela-se cada vez mais patente na medida em que tais sujeitos de direito internacional decidem aprovar novos tratados ou convenções internacionais dessa natureza.

Em abono dessa tese pode-se recordar, como típico acontecimento, a adoção da Convenção sobre Sucessão de Estados em matéria de Bens, Arquivos e Dívidas de Estado, de 8 de abril de 1983, a qual, a exemplo das Convenções sobre Direito dos Tratados, de 1969, e da Convenção sobre Sucessão de Estados em matéria de Tratados, de 1978, recebeu aprovação em Viena, no término da Conferência convocada para esse fim, pela Assembléia Geral da O.N.U. ${ }^{(1)}$.

(1) Vide texto da Convençāo de Viena sovre Sucessão de Estados em matéria de Bens, Arquivos e lóvidas de Estado (United Nations, General Assembly - (A/ Conf. 117 I 14 - 7 April. 1983) in International Legal Materials, vol XXII, number 2, March, 1983, pp. 3()6-327. - A Conferência foi presidida pelo Eminente Professor Ignaz Seidl-Hohenreldern. 
Não mereceu a Convenção de 1983, é verdade, a aprovação unânime dos Estados que integram a sociedade internacional, pois, de acordo com a Ata da Comissão Plenária (Doc. A/ Conf. 117/ C.1/ S.R. 11) somente cinquenta e quatro Estados ofereceram seu assentimento, enquanto que a República Federal da Alemanha, a Bélgica, o Canadá, os Estados Unidos da América, a França, Israel, a Itália, o Luxemburgo, os Países-Baixos, o Reino Unido da Grã-Bretanha e Irlanda do Norte e a Suíça proferiram voto negativo; e de outro lado, os seguintes países abstiveram-se: Austrália, Áustria, Dinamarca, Espanha, Finlandia, Grécia, Islandia, Japão, Noruega, Portugal e Suécia.

Deve-se levar em consideração, todavia, que a Convenção sobre Bens, Arquivos e Dívidas de Estado, como outras convenções ou tratados multilaterais destinados a desenvolver a codificação das normas de direito internacional, requer um período de tempo necessário, como é óbvio, para ter seu reconhecimento definitivo por parte de todos os Estados $^{(2)}$.

\section{II - Caracteres Gerais e Propósitos da Convençāo}

Pelo que respeita aos aspectos formais, a Convenção de Viena sobre a Sucessão de Estados em matéria de Bens, Arquivos e Dívidas de Estado compreende um preâmbulo e um dispositivo elaborado em cinquenta e um artigos, que tratam respectivamente; das Disposições Gerais (Parte I); Bens de Estado (Parte II); Arquivos de Estado (Parte III); Dívidas de Estado (Parte IV); Regulamentação de Controvérsias (Parte V); e Disposiçōes Finais (Parte VI).

Envolve a problemática da Sucessão de Estados, como se sabe, o exame de vários temas tais como os concernentes aos efeitos da substituição da soberania sobre direitos adquiridos; às condiçōes dos habitantes quanto às suas nacionalidades; às influências das transformações territoriais em relação aos atos jurídicos (internos e internacionais); e naturalmente, à delicada questão da responsabilidade internacional do Estado.

No entanto, aplicando método técnico-jurídico mais adequado à codificação das normas de direito internacional e mais condizente com as circunstâncias históricas das relações internacionais contemporâneas, preferiu a Comissão de Direito Internacional não incluir todos os distintos setores da sucessāo de Estados - consoante, aliás, o que reza o Art. 5 da Convenção de 1983 - porém,

(2) Sobre a codificação do direito internacional e seu desenvolvimento progressivo. veja-se, por exemplo a obra de Roberto AC( ) "La Codification du I)roit International ce Les Problèmes de sa Réalisation", in Recucil d'Lidudes de Droit International en Hommage à Paul Guggenheim - Faculté de Droit de l'Université de (ienéve ... Institut Íniversitaire de Hautes Etudes Internationales, Genève, 1968. pp. 93-1.31 
cingir-se à elaboração de um projeto de convenção destinado a regulamentar especificamente as questões sobre bens, arquivos e dívidas de Estado ${ }^{(3)}$.

As questões qualificadas na Convenção de 1983, e que constituem seu objeto, estão enunciadas no preâmbulo do instrumento, a saber, nas transformações da comunidade internacional geradas pelo processo de descolonização; na necessidade da codificação das normas sobre sucessão de Estados, como processo de garantia da segurança jurídica das relações internacionais, tendo em vista a paz e a cooperação; e o respeito à integridade territorial e à independência política de qualquer Estado consoante prescreve a Carta da ONU.

Enfim, é oportuno assinalar que a Convenção de Viena sobre Sucessão de Estados em matéria de Bens, Arquivos e Dívidas de Estado reata, sem alterações "as definiçōes que figuram na Convenção de 1978 (Sucessão de Estados em matéria de Tratados) relativamente aos conceitos de base: sucessão de Estados, Estado predecessor, Estado sucessor, data da sucessão de Estado, Estados recém-independentes"(4).

\section{III - Campo de Aplicação da Convenção}

\section{A) Determinação do Alcance da Convenção}

Em suas disposições gerais, a Convenção estipula que sua aplicação se circunscreve rigorosamente ao regime jurídico internacional da sucessão de Estados em matéria de bens, arquivos e dívidas do Estado (Art. 1), devendo para tanto conformar-se com as normas de direito internacional gerais, e de modo particular com os princípios jurídicos incorporados na Carta da ONU (Artigos 1 e 3).

Quanto ao fator tempo, prescreve basicamente a Convenção em seu Artigo 4, al. 1, que somente será aplicada quando ocorrer uma Sucessão de Estados que se tenha produzido após a entrada em vigor da Convenção; e a Convenção entra em vigor trinta dias após a data em que tenha sido depositado o décimo quinto instrumento de ratificação ou de adesão (Art. 50).

(3) Artigo 5 da Convençāo-: "Nada do disposto na presente Convenção se entenderá de maneira que prejulgue de modo algum nenhuma questão relativa aos efeitos de uma sucessio de listados no concernente às matérias distintas das previstas na presente Conven(ุi)"

(4) ( 1 : MONNILER, Jean, "La Convention de Vienne sur la Successión d'Etats en matiere de Bichs. Archives et Dettes d'Ltat". in Annuaire Français de Droit International, $1984 . X X X . p .223$. 
No que tange aos direitos e obrigações das pessoas naturais ou jurídicas, constituem garantias asseguradas na Convenção, nos termos do Artigo 6. É oportuno assinalar a este respeito, o ensinamento de VERDROSS que assim se expressa: "É indiscutível que os direitos privados adquiridos ao amparo do ordenamento jurídico do Estado não se extinguem ipso-facto com à transformação do Estado e, em princípio, subsistem" "(5).

\section{B) A Transferência dos Bens de Estado}

Ná transferência dos bens de Estado verifica-se desde logo a influência das mutaçōes territoriais sobre o meio econômico. Todas as propriedades estatais, com efeito, situadas no território desmembrado (edifícios públicos, fundos do governo depositados em bancos, estradas de ferro nacionalizadas, navios, aviōes) passam para o Estado sucessor. Nesta ordem de idéias citemos como exemplo expressivo o Artigo 256 do Tratado de Versalhes, de 28 de junho de 1919, que é do teor seguinte: "As Potencias cessionárias de territórios alemães adquirirão todos os bens e propriedades que pertençam ao Império ou aos Estados alemães situados em ditos territórios".

A análise das normas sobre transferência dos bens de Estado contidas na Convenção de 1983 revela uma confirmação de princípios reconhecidos na prática dos Estados. Procurou-se, inicialmente, na Parte II desta Convenção definir a matéria na seguinte forma: "Para os efeitos dos artigos da presente Parte, entende-se por "bens de Estado do Estado predecessor" os bens, direitos, e interesses que na data da sucessão de Estados e de conformidade com o direito interno do Estado predecessor pertenciam a este" (Art. 8).

É na Parte II, Seção 1 (Artigos 9 a 13) da Convenção de 1983 que se encontra regulamentado o capítulo sobre os bens de Estado, cujas regras básicas podem ser assim classificadas:

a) as concernentes aos efeitos da transferência dos bens de Estado, que se realizam sem compensação e que acarretam a extinção dos direitos do Estado predecessor;

b) as que dizem respeito à data da passagem dos bens, a qual deve coincidir com a época da sucessão de Estados;

c) as relativas à ineficácia da sucessão quanto aos bens de um terceiro Estado situados no território do Estado predecessor;

(5) VERDROSS, Alfred - Derecho International Publico, Aguilar, Madrid, 5i lid.. 1967, p. 200. - Acrescente-se, nesta linha de análise a Sentença da (PJl. de lo de sélembro de 1923 - (Colonos alcmács na Polonia) - B. 6. p. 36. "L.es droits privés alcyuis conformement aux droits en vigueur, ne deviennent point caducs à ta suite d'un changement de souveraineté". 
d) as regras que dizem respeito à conservação e segurança dos bens de Estado.

Reservou a Convenção em sua Seção 2, da Parte II, um espaço destinado a regulamentar as categorias especííicas da Sucessão de Estados. Trata-se dos seguintes tópicos:

a) transferência de uma parte do território de um Estado, caso em que dita transferência se opera por acordo obtido entre os Estados predecessor e sucessor, ou em ocorrendo falta desse acordo, os bens imóveis e os bens móveis passam (automaticamente) do Estado predecessor ao Estado sucessor (Art. 14);

b) sistemática dos bens de Estados que alcançaram a independência recentemente (Art. 15);

c) unificação de Estados (Art. 16);

d) separaçāo de parte ou partes do territorio de um Estado (Art. 17);

e) dissolução de um Estado (Art. 18).

\section{C) - A Transferência dos Arquivos de Estado}

Segundo CH. ROUSSEAU "Embora não se possa refutar seu caráter público, a transferência dos arquivos tem suscitado por vezes, complicaçōes, mas sempre se admitiu que a propriedade dos arquivos conservados pela administração local segue o destino do território e se transfere com este ao Estado sucessor" ${ }^{(6)}$.

A aplicação dessa regra pode ser constatada no Artigo 52 do Tratado de Versalhes - no Capítulo sobre a reintegraçāo da Alsacia-Lorena à soberania francesa. Assim determinava o Artigo 52: "O Governo alemão entregará sem delonga ao Govemo francês os arquivos, registros, planos, títulos e documentos de todas as classes referentes à administraçāo civil, militar, financeira, judicial ou de outra índole dos territórios reintegrados à soberania francesa".

Ora, a Convenção de 1983 renova esses conceitos na definição contida em seu Artigo 20, nos seguintes termos:

Art. 20: "Para os efeitos dos artigos da presente parte, se entende por 'arquivos de Estado do Estado predecessor' todos os documentos, sejam quais forem sua data e natureza, produzidos ou recebidos pelo Estado predecessor no exercício de suas funções que,

(6) ROUSSI:Al, (harles - Dercho Internacional Publico, Ed. ARIEL, 3arcelona, 3: deçiōo. 1960, p. 27.3. 
na data da sucessão de Estados, pertenciam ao Estado predecessor de conformidade com seu direito interno e eram conservados por ele diretamente ou sob seu controle em qualidade de arquivos com qualquer fim".

Quanto aos efeitos da passagem dos arquivos de Estado predecessor e notadamente às questões relativas à conservação e segurança dos arquivos, aos Estados nascidos de descolonização (recente) e dissolução de um Estado, acham-se disciplinadas nos Artigos 21 a 31 da Convenção.

\section{D) A Transferência das Dívidas de Estado}

A Parte IV da Convenção de Viena de 1983, Artigos 32 a 41, assenta os princípios que envolvem a questão das dívidas de Estado quando ocorre a sucessão entre Estados. Dentro deste contexto cabe destacar a definição de dívida de Estado e as condições soberanas (bens, direitos e interesses) no que tange aos Estados provindos da descolonização e assim merecedores de um tratamento mais vantajoso pelo que respeita ao direito adotável aos outros Estados sucessores.

Segundo o Artigo 33, "Para os efeitos dos artigos da presente parte entende-se por 'dívida de Estado' toda obrigação financeira de um Estado predecessor para com outro Estado, para com uma organização internacional ou para com qualquer outro sujeito de direito internacional, nascida de conformidade com o direito internacional". Percebe-se, desde logo, que a Convençāo se refere às dívidas contraídas pelo Estado (predecessor) de acordo com as normas do sistema jurídico internacional, porquanto este sistema jurídico não comina e não pode cominar a nenhum Estado deveres para com seus próprios nacionais ${ }^{(7)}$.

Os preceitos basilares sobre as dívidas de Estado, consagrados no Artigo 38 da Convenção de Viena em epígrafe, referem-se notadamente aos Estados tornados independentes recentemente. Os Estados sucessores com estas características, de fato, nāo contraem as dívidas do Estado predecessor, a menos que tenham celebrado acordo sobre a liquidação dessas dívidas. E o parágrafo 2 do Artigo 38 reafirma que "o acordo a que se refere o parágrafo 1 não poderá infringir o princípio da soberania permanente de cada povo sobre suas riquezas e seus recursos naturais, nem seu cumprimento poderá colocar em perigo os equilíbrios econômicos fundamentais do Estado de recente independência".

\section{E) A Regulamentação das Controvérsias}

Prevê a Convenção de 1983, Parte V, diversos mecanismos que visam à solução de controvérsias surgidas entre duas ou mais Partes signatárias. O Arti-

(7) Cf: VERDF.OSS, Alfred - op. cit. p. 196-197. 
go 42 da Convenção enuncia o princípio de que é obrigatório recorrer a um modo pacífico de solução de conflitos. Todavia, da mesma forma que em outros instrumentos convencionais, os Estados signatários mantêm a liberdade de escolher o modo de solução apropriado a um caso concreto.

Dessarte, nos termos do Artigo 42, quando surgir uma controvérsia a respeito da interpretação ou da aplicação da Convenção entre dois ou mais Estados pactuantes, tentar-se-á encontrar solução mediante um processo de consulta e negociação. Não resolvido o litígio no prazo de seis meses devem então as Partes em questăo submetê-la ao processo de conciliação (Art. 43). Todavia, a solução de controvérsias pelos meios judicial, arbitral ou outra, estabelecida de comum acordo entre as Partes, é prevista nos Artigos 44 e 45 da Convenção.

\section{Conclusōes}

A Convenção de Viena de 1983, que envolve três aspectos fundamentais do Direito das Sucessões de Estados (Bens, Arquivos e Dívidas) constitui um todo indivisível e as regras nela enunciadas, como ensina MONNIER "ont dans l'ensemble un caractère supplétif et se présentent comme des règles types, celles-ci se voient dotées dans le cas de succession resultant de l'accession a l'indépendance, comme dans les cas de séparation d'une partie du territoire d'un Etat ou d'une dissolution d'Etats à propos des archives, d'une armature parajuridique destinée à en préserver l'intégrité" ${ }^{(8)}$.

Em conclusão, pode-se afirmar que o maior mérito da Convenção consistiu em preencher uma lacuna no âmbito do Direito das Sucessōes de Estado (especialmente, é claro, em matéria de bens, arquivos e dívidas de Estado), bem como em dinamizar o processo de codificaçáo do direito internacional e seu desenvolvimento progressivo, evidenciando-se por tal modo o efetivo cumprimento do preceituado no Artigo 13 da Carta da O.N.U.

\section{BIBLIOGRAFIA}

BEDJ AQUI. Mohammed - “Problèmes récents de Sucoession d'Etats dans les Etats nouveaux" in Réceuil dés Cours de l’Académie de Droit International de la Haye, 1970.

I.)NT BI.A\%QUL:. Agustin - "La Conferencia de Viena sobre la sucesión de Estados en materia de bienes, archivos y deudas de Estado", in Revista Española de Derecho International. 1984. XXXVI, n. 1, pp. 39 ess.

(8) ('l: MIONNII:R, jean -- op. cit. p. 227. 
MONNIER, Jean - (1) - “Observations sur la Codification et le développement progressif du droit international”, Mélanges à Georges Perrin, Lausanne, 1984 - pp. 237-249 - (2) - "La Convention de Vienne sur la succession d'Etats en matière de Biens, Archives et Dettes d'Etats" in Annuaire Français de Droit International, 1984, XXX, pp. 221 e ss.

O’CONNELL, D.P. - “Recent Problems of State Succession in Relation to New States”, in Recueil des Cours de l'Académie de Droit International de la Haye, 1970, II, pp. 198 ss.

SEIDL-HOHENVELDERN, Ignaz - "Das Wiener Übereinkommen über Staatennachfolge in Vermōgen, Archive, und Schulden von Staaten" in Österreichiche Zeitschrift für.Öffentliches Recht und Völkerrecht, 1983, pp. 173-199.

STREINZ, Rudolf - "Succession of States in Assets and Liabilities. A New Regime? The 1983 Vienna Convention on Succession of States in Respect of State Property, Archives and Debts" in German Yearbook of International Law, 1983, pp. 198-237. 